\title{
Urgences
}

\section{Bernard Boucher, Ravaudage, Rimouski, Éditeq, 1982.}

\section{Marie Bélisle}

Numéro 7, 2e trimestre 1983

URI : https://id.erudit.org/iderudit/025110ar

DOI : https://doi.org/10.7202/025110ar

Aller au sommaire du numéro

Éditeur(s)

Urgences

ISSN

0226-9554 (imprimé)

1927-3924 (numérique)

Découvrir la revue

Citer ce compte rendu

Bélisle, M. (1983). Compte rendu de [Bernard Boucher, Ravaudage, Rimouski, Éditeq, 1982.] Urgences, (7), 88-89. https://doi.org/10.7202/025110ar

Ce document est protégé par la loi sur le droit d'auteur. L’utilisation des services d'Érudit (y compris la reproduction) est assujettie à sa politique d'utilisation que vous pouvez consulter en ligne.

https://apropos.erudit.org/fr/usagers/politique-dutilisation/
Cet article est diffusé et préservé par Érudit.

Érudit est un consortium interuniversitaire sans but lucratif composé de l’Université de Montréal, l'Université Laval et l'Université du Québec à Montréal. Il a pour mission la promotion et la valorisation de la recherche. https://www.erudit.org/fr/ 
RAVAUDAGE, Bernard Boucher, ÉDITEQ, Rimouski, 1982.

"Ravauder: rôder, vagabonder, aller ça et là"

Cette petite définition, placée en exergue du dernier texte du recueil de Bernard Boucher nous donne, à postériori, une espèce de clef de lecture de Ravaudage.

En effet, le recueil est constitué de petits textes, regroupés en une dizaine de séries indépendantes les unes des autres, posées comme des balises.

Ce mode de construction permet à l'auteur de "disséquer" son propos, de le faire apparaître au lecteur pièce par pièce. Chacun des textes ne prend sa réelle dimension qu'au contact de l'ensemble de la série dont il fait partie. Les poèmes se répondent, certains mots tracent les lignes de rappel.

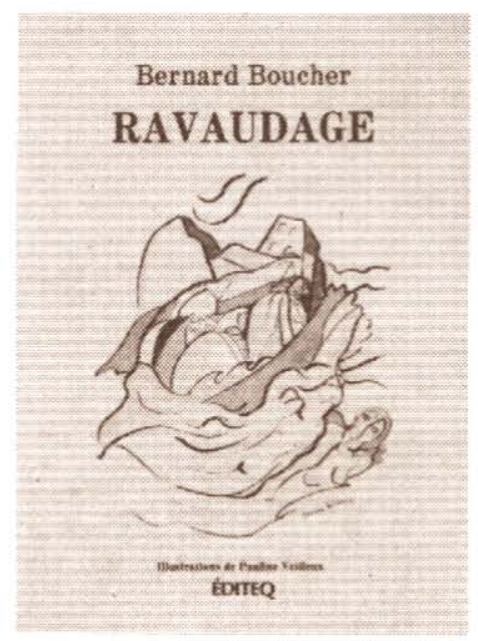

D'une série à l'autre, le lecteur appréhende l'univers morcelé de Bernard Boucher, cet univers de la difficile tendresse, cet univers menacé par "I'héritage des soupçons", "le bitume des normes", "le danger des carrières", le "conditionnel social". 
Toutefois, quelques "glissements" dans I'élan poétique viennent parfois rendre la lecture de l'émotion un peu difficile. Les images semblent s'arrêter en cours d'écriture, le propos bifurque, et on cherche en vain, à certains moments, le mot qui permettrait au texte de retomber sur ses pieds. Les écarts syntaxiques propres à l'écriture poétique ne sont pas toujours parfaitement contrôlés. Certaines répétitions viennent aussi parfois affaiblir l'image, la rendre presque banale (retour du mot "tendresse", redondance des images construites à partir de "la lune"). On perd donc un peu l'effet d'étonnement qui fait la force du poème.

Tant dans la structure du texte que dans son contenu, le lecteur sent une cassure dans l'émotion. Peut-être certains resteront-ils un peu sur leur faim... Mais cette difficulté à écrire la tendresse et le désarroi ne peut-elle pas être interprétée comme la traduction dans le corps même du poème de la difficulté que peut éprouver l'auteur à assumer ses élans...?

Retenons après tout cela, quelques images superbes et fortes, constituant souvent un texte à elles seules: ces petits poèmes placés en exergue de quelques séries ou, imprimés en italiques, marquant la fin d'une suite par de petits points de suspension:

"les mots dans une main

le mors des phrases

coincé dans nos corps irascibles" (p. 40)

"tout simplement la mer qui bat

nappée de nos voyages" (p. 96)

"as-tu déjà pensé

au surgissement

du mois de janvier" (p. 99)

Peut-être simplement pourrions-nous souhaiter en terminant que Bernard Boucher, dans un prochain recueil "ravaude" un tout petit peu moins au niveau du style, et un peu plus profondément dans ses désirs et ses angoisses. II ne s'agit somme toute que d'affiner l'élan.

Marie Bélisle 